\title{
Jurisdição Constitucional como mecanismo de emancipação social: uma abordagem a partir de decisões da Corte Constitucional colombiana sobre direitos sociais ${ }^{1}$
}

\author{
Judicial Review as a mechanism of social emancipation: an approach from decisions of the \\ Colombian Constitutional Court on social rights
}

Alessia Barroso Lima Brito Campos Chevitarese*

Ana Borges Coêlho dos Santos**

Camila Nascimento de Souza ${ }^{* * *}$

\begin{abstract}
REFERÊNCIA
CHEVITARESE, Alessia Barroso Lima Brito Campos; SANTOS, Ana Borges Coêlho dos; SOUZA. Camila Nascimento de. Jurisdição Constitucional como mecanismo de emancipação social: uma abordagem a partir de decisões da Corte Constitucional colombiana sobre direitos sociais. Revista da Faculdade de Direito da UFRGS, Porto Alegre, n. 42, p. 124-149, abr. 2020. DOI: <https://doi.org/10.22456/0104-6594.84537>.
\end{abstract}

\section{RESUMO}

$\mathrm{O}$ artigo tem por objetivo analisar a efetividade da jurisdição constitucional como mecanismo de emancipação social de determinados grupos a partir de decisões da Corte Constitucional colombiana. Nesse sentido, busca-se compreender a tutela dos direitos sociais, conforme o disposto na Constituição Colombiana de 1991, e os desafios de implementação dos direitos previstos, bem como o contexto de desenvolvimento de um protagonismo mais acentuado da Corte Constitucional colombiana. O estudo investiga se as progressistas decisões da citada Corte são capazes de modificar positivamente a situação social de grupos socialmente vulneráveis, com a finalidade de ponderar, nesse contexto, o papel da jurisdição constitucional na efetividade dos direitos sociais dos jurisdicionados.

\section{PALAVRAS-CHAVE}

Corte Constitucional da Colômbia. Emancipação social. Efetividade dos direitos sociais.

\section{ABSTRACT}

The article aims to analyze the effectiveness of judicial review as a mechanism of social emancipation of certain groups based on decisions of the Colombian Constitutional Court on social rights. In this sense, we seek to understand the protection of social rights, in accordance with the Colombian Constitution of 1991 and the challenges of implementing the rights envisaged, as well as the context of developing a more prominent role of the Colombian Constitutional Court. The study investigates whether if the progressive decisions of the aforementioned Court are capable of positively changing the social situation of socially vulnerable groups, in order to consider, in this context, the role of constitutional jurisdiction in the effectiveness of the social rights.

\footnotetext{
1 Este trabalho é produto da pesquisa desenvolvida no âmbito do grupo Cortes Constitucionais e Democracia (linha: constitucionalismo latino-americano), coordenado pelas professoras Patrícia Perrone Campos Mello e Aléssia Barroso Lima Brito Campos Chevitarese. Diretório dos Grupos de Pesquisa no Brasil, Plataforma Lattes: dgp.cnpq.br/dgp/espelhogrupo/7629538930156064.

* Doutora e Mestre - Centro Universitário de Brasília (UniCEUB). Professora da Clínica de Direitos Humanos do UniCEUB. Membro do Centro Brasileiro de Estudos Constitucionais (CBEC).

** Subprocuradora-Geral da República com atuação no Superior Tribunal de Justiça, mestre em Direito e Especialista em Direitos Sociais, Ambiental e do Consumidor pelo UniCEUB. Membro do Grupo de Pesquisa: Cortes Constitucinais e Democracia (UniCEUB).

*** Advogada e aluna especial do Programa de Pós-Graduação em Direito da Universidade de Brasília (UNB). Membro do Centro Brasileiro de Estudos Constitucionais Universitário (CBEC Universitário). Membro do Grupo de Pesquisa: Cortes Constitucinais e Democracia (Centro Universitário de Brasília - UniCEUB).
} 
KEYWORDS

Colombian Constitutional Court. Social emancipation. Effectiveness of social rights.

\section{SUMÁRIO}

1. Introdução. 2. A garantia dos direitos sociais na aspiracional Constituição colombiana de 1991. 3. A implementação dos direitos sociais e a atuação da Corte Constitucional: uma análise do ativismo judicial progressista. 4. A doutrina da conexidade como critério de proteção de direitos sociais por via da Ação de Tutela. 5. As tipologias de sentença sobre direitos sociais da Corte colombiana. 6. Decisões paradigmáticas da Corte colombiana na proteção de direitos sociais. 7. A efetividade das decisões da Corte colombiana como mecanismo de emancipação social. 8. Conclusão. Referências. Dados da publicação.

\section{INTRODUÇÃO}

A Corte Constitucional da Colômbia, estabelecida em 1991 com a nova Constituição, inaugurou um importante momento jurídico e social para o país. Após um processo histórico conturbado, marcado pela violência, que atingiu o próprio Supremo Tribunal, no episódio da tomada do Palácio da Justiça em 1988, com a morte de muitos de seus juízes e um período de 35 anos no antigo Estado de Sítio $^{2}$, a nova Corte Constitucional nasceu com o desafio de garantir a guarda da Constituição e, mais do que isso, construir seu significado e decidir sobre a sua relevância na vida dos cidadãos colombianos ${ }^{3}$. Nesse contexto, em meio à dura realidade política, social e econômica do país, a Corte colombiana passou a julgar questões relevantes, formando uma jurisprudência forte e criativa, especialmente na implementação dos direitos sociais ${ }^{4}$.

2 Segundo Rodrigo Uprimny Yepes, “[...] desde o fechamento temporário do Congresso durante o governo de Ospina Pérez (1946-1950), em novembro de 1949, até a promulgação da Constituição de 1991, a Colômbia viveu praticamente em um regime de exceção permanente, pois, desses 42 anos, 35 transcorreram sob estado de sítio". UPRIMNY YEPES, Rodrigo. A judicialização da política na Colômbia: casos, potencialidades e riscos. Sur, Rev. int. direitos human., São Paulo, v. 4, n. 6, p. 52-69, 2007. Disponível em: http://www.scielo.br/scielo.php?script=sci_arttext\&pid=S1806-64452007000100004\&lng=en\&nrm=iso. Acesso em: 3 maio 2018.

Cumpre ainda destacar que a atual Constituição não mais possui previsão do Estado de Sítio, mas foi substituído pelo "estado de conmoción interior" conforme asseveram Revenga-Sánchez e Girón-Reguera. REVENGASÁNCHEZ, Miguel; GIRÓN-REGUERA, Emilia. La Corte Constitucional colombiana ante las medidas de seguridad y defensa nacional del gobierno de Uribe. Estudios Socio-Jurídicos, v. 6, n. 1, p. 29-57, jan.jun. 2004. Disponível em: https://revistas.urosario.edu.co/index.php/sociojuridicos/article/view/274/223. Acesso em: 1 maio 2018.

3 Enrique Neira apresenta um relato da violência na Colômbia no período que antecedeu a Constituição de 1991, em sua multiplicidade de formas e atores, dos quais indica como principais os vários grupos guerrilheiros, que datam dos anos de 1960, os grupos exterminadores, que afirma chamados inadequadamente de autodefesa ou paramilitares, e os grandes cartéis de narcotráfico, cujo poder econômico se mescla com os demais, caracterizando-se como os maiores geradores de violência na Colômbia. Retrata a atuação do Movimento 19 de Abril (M-19), com menos efetivos do que a FARC, com ações chamativas de feitio terrorista e midiático, dentre as quais destaca o roubo da espada de Bolívar, o roubo de armas do "Cantón Norte" do Exército de Bogotá, a tomada da Embaixada da República Dominicana e o ataque ao Palácio da Justiça em 1988. NEIRA, Enrique. Un caso intrincado de violencia: Colombia. Nueva Sociedad, n. 105, p. 141-152, jan./fev. 1990. Disponível em: http://nuso.org/media/articles/downloads/1840_1.pdf. Acesso em: 9 maio 2018.

4 LANDAU, David. Judicial role and the limits of constitutional convergence in Latin America". In: DIXON, Rosalind; GINSBURY, Tom (ed.). Comparative constitutional law in Latin America, 2017. Disponível em: 
A Corte colombiana assumiu, assim, o papel de protagonista da nova Constituição, do tipo aspiracional, ligada a uma forte ideia de progresso social, mais bem compreendida na realidade histórica em que foi construída. A ideia de Constituição aspiracional, como afirma García Villegas ${ }^{5}$, prospera principalmente em situações nas quais existe uma grande inconformidade com o presente e uma forte crença nas possibilidades de um futuro melhor. No Direito Constitucional, como também observa García Villegas ${ }^{6}$, é particularmente evidente a ambiguidade entre um olhar discursivo para o presente e aquele que olha para $o$ futuro, isto é, entre o discurso legal e o discurso político. São constituições que se revelam pelo objetivo de alcançar o progresso social e um futuro melhor para a sociedade. São constituições que visam ao futuro e prescrevem o que deve ser alcançado ao longo dos anos.

Nessa realidade, a Corte colombiana passou a decidir de forma progressista ${ }^{7}$ e em favor dos direitos sociais de grupos específicos, como minorias, populações estigmatizadas ou em situação de fraqueza política, além da interferência em políticas econômicas em virtude da proteção de direitos sociais, construindo um dos mais alargados ativismos progressistas no ambiente latino-americano, o que permite examinar a sua atuação sob o foco da jurisdição constitucional como mecanismo de emancipação social ${ }^{8}$.

Para a análise proposta neste trabalho, que se centra na jurisdição constitucional como mecanismo de emancipação social, serão primeiramente explicitados os conceitos e ideias que norteiam o presente artigo, em que se toma como contexto o ativismo judicial progressista da Corte colombiana e os obstáculos históricos que dificultam a produção de efetivas mudanças sociais. Parte-se da proposta feita por María Paula Saffon e Mauricio García Villegas ${ }^{9}$ em

https://ssrn.com/abstract=2907075. Acesso em: 9 abr. 2018.

5 GARCÍA VILLEGAS, Mauricio. Constitucionalismo Aspiracional: Derecho, Democracia y Cambio Social en América Latina. Análisis Político, v. 25, n. 75, p. 89-110, maio 2012. Disponível em: https://revistas.unal.edu.co/ index.php/anpol/article/view/43508/44797. Acesso em: 15 abr. 2018.

6 Id. Constitucionalismo aspiracional. Araucaria. Revista Iberoamericana de Filosofía, Política y Humanidades, v. 15, n. 29, 2013. Disponível em: http://www.redalyc.org/html/282/28225781004/. Acesso em: 28 maio 2017.

7 Segundo afirmam María Paula Saffon e Mauricio García Villegas, é preciso não confundir ativismo com progressismo judicial. $\mathrm{O}$ ativismo não necessariamente é progressista. Conforme defendem esses autores, o melhor exemplo de ativismo conservador é presente na atuação da Suprema Corte norte-americana no início do século XX. SAFFON, María Paula; GARCÍA VILLEGAS, Mauricio. Derechos sociales y activismo judicial. La dimensión fáctica del activismo judicial en derechos sociales en Colombia. Revista Estudios Socio-Jurídicos, v. 13, n. 1, p. 75-107, jan./jun. 2011. Disponível em: http://www.redalyc.org/html/733/73318918004/. Acesso em: 05 dez. 2017.

8 LANDAU, David. Judicial role and the limits of constitutional convergence in Latin America". In: DIXON, Rosalind; GINSBURY, Tom (ed.). Comparative constitutional law in Latin America, 2017. Disponível em: https://ssrn.com/abstract=2907075. Acesso em: 9 abr. 2018.

9 Realizado em duas etapas, o estudo se constituiu, primeiramente, em investigação, a partir das decisões da Corte Constitucional entre 1992 e 1996. A primeira publicação ocorreu em 2001, por García Villegas. Já a segunda etapa, que complementa e aprofunda os estudos das decisões, pesquisou dos anos de 1996 a 2006, e foi publicada em 2011. SAFFON; GARCÍA VILLEGAS, op. cit. 
estudo empírico das decisões em direitos sociais da Corte Constitucional da Colômbia entre 1992 e 2006.

Serão também analisadas as tipologias de sentença sobre direitos sociais da Corte colombiana e a doutrina da conexidade, um importante critério que proporcionou a proteção dos direitos sociais através das Ações de Tutela.

Em seguida, serão explicitadas algumas decisões consideradas paradigmáticas da Corte colombiana na proteção de grupos sociais e, por fim, será analisada a efetividade das suas decisões em direitos sociais, a se perscrutar a jurisdição constitucional como importante mecanismo de emancipação social, e não apenas retórica de solidariedade para manter a esperança de cidadania no âmbito social.

\section{A GARANTIA DOS DIREITOS SOCIAIS NA ASPIRACIONAL CONSTITUIÇÃO COLOMBIANA DE 1991}

A atual Constituição política colombiana de 1991 tutela direitos sociais antes não abarcados na Constituição de 1886. Na nova Constituição social colombiana ${ }^{10}$, o Estado é definido como um Estado social de direito, democrático e pluralista, marco dentro do qual devem se realizar os fins essenciais do Estado. A Carta de 1991 proclamava, ainda, a supremacia da Constituição como "norma das normas" e sua prevalência em caso de incompatibilidade com outra norma jurídica, e cujo amplo catálogo de direitos se fez acompanhar de mecanismos aptos para sua proteção, notadamente da acción de tutela, conhecida em outros países como "recurso de amparo", através da qual, nos moldes da previsão contida em seu artigo $86^{11}$, em procedimento preferente e sumário, é possível se

10 Brinks e Blass observam que as denominadas "Constituições sociais”, como a Constituição do Brasil de 1988 e a Constituição da Colômbia de 1991, que marcam um período de novas constituições no espaço latinoamericano, apresentam-se com uma mais densa versão de justiça constitucional visando à democratização através da promoção da inclusão social e econômica, com extenso catálogo de direitos sociais e econômicos e Cortes de justiça desenhadas com papéis políticos importantes. BRINKS, Daniel M.; BLASS, Abby. The DNA of constitutional justice in Latin America: politics, governance and judicial design. New York, NY: Cambridge University Press, 2018. Capítulo 1, 1.1.

11 No original: "Artículo 86. Toda persona tendrá acción de tutela para reclamar ante los jueces, en todo momento y lugar, mediante un procedimiento preferente y sumario, por sí misma o por quien actúe a su nombre, la protección inmediata de sus derechos constitucionales fundamentales, cuando quiera que éstos resulten vulnerados o amenazados por la acción o la omisión de cualquier autoridad pública. La protección consistirá en una orden para que aquel respecto de quien se solicita la tutela, actúe o se abstenga de hacerlo. El fallo, que será de inmediato cumplimiento, podrá impugnarse ante el juez competente y, en todo caso, éste lo remitirá a la Corte Constitucional para su eventual revisión. Esta acción solo procederá cuando el afectado no disponga de otro medio de defensa judicial, salvo que aquella se utilice como mecanismo transitorio para evitar un perjuicio irremediable. En ningún caso podrán transcurrir más de diez días entre la solicitud de tutela y su resolución. La ley establecerá los casos en los que la acción de tutela procede contra particulares encargados de la prestación de un servicio público o cuya conducta afecte grave y directamente el interés colectivo, o respecto de quienes el 
reclamar perante os juízes, por si mesmo ou por alguém que atue em seu nome, a proteção imediata de direitos constitucionais fundamentais ${ }^{12}$.

A realização da igualdade substancial como meta constitucional, o extenso catálogo de direitos e os instrumentos de acesso à jurisdição favoreceram a ação da Corte colombiana em adotar mais facilmente medidas em favor de uma maior igualdade social, assim como a proteção de grupos sociais excluídos e sem representatividade efetiva. Além disso, para além da mudança da própria Constituição, ocorreu uma mudança de comportamento do Tribunal. A anterior Corte Suprema comportava-se de maneira a reconhecer seu papel organicista e voltado para aspectos e competências, pois “[...] entendia que sua função não era tanto definir o alcance dos direitos, mas essencialmente assegurar que a divisão de competências entre os distintos órgãos do Estado fosse respeitada"13, o que resultou numa jurisprudência escassa e tímida em matéria de direitos constitucionais.

Na prática, os direitos sociais na Constituição colombiana de 1991 poderiam ter uma eficácia puramente retórica e legitimadora da ordem dominante. Mas a composição da nova Corte, em face das mudanças constitucionais, propiciou uma atuação ativista progressista, na medida em que seus magistrados decidiram naquele novo contexto político, dar um impulso aos conteúdos emancipadores da Carta de $1991^{14}$.

Assim, diante da intenção gravada na nova Constituição, de criar um modelo de sociedade cujos princípios orientadores incluíram a ampliação dos mecanismos de participação, o êxito da justiça social, a igualdade e a proteção, com a garantia efetiva de um amplo conjunto de direitos constitucionais, em "[...] uma generosa carta de direitos composta por direitos civis e políticos, assim como direitos sociais, econômicos, culturais, coletivos e do meio ambiente" ${ }^{15}$, dentro de um constitucionalismo aspiracional.

solicitante se halle en estado de subordinación o indefensión." COLÔMBIA. Constitución Política de Colombia, de 6 de julho de 1991. Disponível em: http://www.corteconstitucional.gov.co/inicio/Constitucion\%20politica $\% 20 \mathrm{de} \% 20$ Colombia.pdf. Acesso em: 3 maio 2018.

12 BORDA, Luis Villar. Influencia de Kelsen en el actual sistema colombiano de control jurisdiccional de la Constitución. Revista Derecho del Estado, n. 9, p. 17-29, dez. 2000. Disponível em: http://revistas.uexternado.edu.co/index.php/derest/article/view/877/832. Acesso em: 9 maio 2018.

13 UPRIMNY YEPES, Rodrigo. A judicialização da política na Colômbia: casos, potencialidades e riscos. Sur, Rev. int. direitos human., São Paulo, v. 4, n. 6, p. 52-69, 2007. Disponível em: http://www.scielo.br/scielo.php? script=sci_arttext\&pid=S1806-64452007000100004\&lng=en\&nrm=iso. Acesso em: 3 maio 2018.

14 UPRIMNY, Rodrigo; GARCÍA VILLEGAS, Maurício. Tribunal constitucional e emancipação social na Colômbia. In: SANTOS, Boaventura de Sousa (org.). Democratizar a democracia: os caminhos da democracia participativa. Rio de Janeiro: Civilização Brasileira, 2002. p. 297-339.

15 SAFFON, María Paula; GARCÍA VILlEGAS, Mauricio. Derechos sociales y activismo judicial. La dimensión fáctica del activismo judicial en derechos sociales en Colombia. Revista Estudios Socio-Jurídicos, v. 13, n. 1, p. 75-107, jan./jun. 2011. Disponível em: http://www.redalyc.org/html/733/73318918004/. Acesso em: 05 dez. 2017. 
Como observa García Villegas ${ }^{16}$, dentre as principais características que integram os distintos processos de renovação constitucional ocorridos na América Latina nas últimas décadas está o constitucionalismo aspiracional, o qual articula as noções de Constituição e progresso, e prospera, sobretudo em situações nas quais existe uma grande inconformidade com o presente e uma forte crença nas possibilidades de um futuro melhor. A Constituição aspiracional, portanto, é meio articulador de progresso. Implica uma visão de futuro, onde não só se plantam regras político-jurídicas para situações problemáticas para o Estado no presente, mas também que possibilitam a projeção da integridade do Estado a instâncias posteriores no tempo ${ }^{17}$. Concretiza a esperança por uma sociedade melhor e mais justa ${ }^{18}$.

\section{A IMPLEMENTAÇÃo dOS DIREITOS SOCIAIS E A ATUAÇÃO DA CORTE CONSTITUCIONAL: UMA ANÁLISE DO ATIVISMO JUDICIAL PROGRESSISTA}

A Assembleia Constituinte que deu origem à Constituição colombiana de 1991 foi bastante heterogênea, formada por vários setores sociais e políticos, inclusive aqueles que, tradicionalmente excluídos, tiveram a oportunidade de participar ativamente do processo de elaboração da nova Constituição: minorias políticas e religiosas, povos indígenas, comunidades afrodescendentes, movimentos estudantis, entre outros ${ }^{19}$. Porém, muitos desses participantes, após a promulgação, acabaram desmobilizados e saíram da arena política. Como consequência, a Constituição de 1991, repleta de "promessas", principalmente no âmbito social, não pôde contar com os mesmos atores políticos para torná-la efetiva, nos anos posteriores. Diante dessa omissão, prosperou a reação dos grupos mais conservadores, como as agências econômicas internacionais que, na prática, incentivaram o governo colombiano a aplicar estratégias de liberalização econômica e consequente redução da intervenção do Estado na economia ${ }^{20}$.

16 GARCÍA VILLEGAS, Mauricio. Constitucionalismo aspiracional: derecho, democracia y cambio social en América Latina. Análisis Político, v. 25, n. 75, p. 89-110, maio 2012. Disponível em: https://revistas.unal.edu.co/ index.php/anpol/article/view/43508/44797. Acesso em: 15 abr. 2018.

17 MOLINA, Jorge Enrique León. Constitucionalismo aspiracional y paz: entre la democracia y la opinión. Soft Power, v. 3, n. 1, p. 209-218, 2017.

18 García Villegas refere-se ao amplo catálogo de direitos presente nas constituições aspiracionais como um "catálogo de esperanças" por uma sociedade melhor e mais justa. GARCÍA VILLEGAS, op. cit.

19 SAFFON, María Paula; GARCÍA VILLEGAS, Mauricio. Derechos sociales y activismo judicial. La dimensión fáctica del activismo judicial en derechos sociales en Colombia. Revista Estudios Socio-Jurídicos, v. 13, n. 1, p. 75-107, jan./jun. 2011. Disponível em: http://www.redalyc.org/html/733/73318918004/. Acesso em: 05 dez. 2017.

20 Ibid. 
A falta de outros atores políticos na arena legislativa, potencializada pela clara tensão entre as cláusulas econômicas neoliberais e as promessas sociais do novo texto constitucional, levou a Corte Constitucional a se apresentar como uma das poucas instituições dispostas a defender as cláusulas sociais e o conteúdo progressista da Constituição. Ressalta-se, ainda, que várias instituições estatais, ao privilegiarem as políticas neoliberais, colocavam-nas acima das políticas sociais. E, ao mesmo tempo, propunham reformas para diminuir os poderes da Corte, ao considerarem o seu ativismo progressista como uma violação ao princípio da separação de poderes e como um obstáculo ao desenvolvimento econômico. Em linhas gerais, esse cenário de déficit de vontade política de desenvolver o projeto constitucional emancipatório e os conflitos interinstitucionais, além da resistência conservadora de alguns membros de setores do Estado, permite compreender o contexto que possibilitou a existência de um forte ativismo judicial em direitos sociais na atuação da Corte colombiana ${ }^{21}$.

A esses fatores acrescenta-se o histórico colombiano de violência, com a presença de vários grupos guerrilheiros, grupos exterminadores e dos grandes cartéis de narcotráfico, destacando-se as FARC-EP, Fuerzas Armadas Revolucionarias de Colombia - Ejército del Pueblo, como uma das guerrilhas mais antigas, remontando ao final de $1947^{22}$. Após décadas de conflito, um acordo de paz foi firmado em 2016, com a definição de um programa de resiliência, conceito fundamental no cenário pós-conflito.

Uprimny e García Villegas agrupam esses elementos que propiciaram o comportamento ativista progressista da Corte colombiana em três fatores jurídicoinstitucionais e dois políticos-estruturais. Os dois fatores político-estruturais são a crise de representação e a debilidade dos movimentos sociais e dos partidos de oposição, ao que se acrescenta uma tradição histórica de movimentos sociais débeis e, diante do quadro de violência, os assassinatos de muitos líderes e ativistas, tudo a conduzir à explicação de que o desencanto dos colombianos com a política levou certos setores a exigirem do Poder Judiciário respostas a problemas que, em princípio, deveriam ser debatidos e resolvidos diante da mobilização cidadã nas esferas políticas ${ }^{23}$.

21 SAFFON, María Paula; GARCÍA VILlEGAS, Mauricio. Derechos sociales y activismo judicial. La dimensión fáctica del activismo judicial en derechos sociales en Colombia. Revista Estudios Socio-Jurídicos, v. 13, n. 1, p. 75-107, jan./jun. 2011. Disponível em: http://www.redalyc.org/html/733/73318918004/. Acesso em: 05 dez. 2017.

22 NEIRA, Enrique. Un caso intrincado de violencia: Colombia. Nueva Sociedad, n. 105, p. 141-152, jan./fev. 1990. Disponível em: http://nuso.org/media/articles/downloads/1840_1.pdf. Acesso em: 9 maio 2018.

23 UPRIMNY, Rodrigo; GARCÍA VILLEGAS, Maurício. Tribunal constitucional e emancipação social na Colômbia. In: SANTOS, Boaventura de Sousa (org.). Democratizar a democracia: os caminhos da democracia participativa. Rio de Janeiro: Civilização Brasileira, 2002. p. 297-339. 
Enquadrados como fatores jurídico-institucionais para o comportamento da Corte colombiana estão a longa tradição de controle judicial de constitucionalidade, pois desde 1910 já se reconhecera ao Supremo Tribunal de Justiça a possibilidade de declarar, com poder geral, a inconstitucionalidade de uma lei; o próprio desenho processual que possibilita o fácil acesso à justiça constitucional e a conformação do enorme poder jurídico conferido à Corte ${ }^{24}$.

Assim, o quadro político da Colômbia e, principalmente, o acesso à justiça constitucional propiciaram o ativismo progressista da Corte Constitucional colombiana na implementação dos direitos sociais, ao que se acrescenta a esse protagonismo o desenvolvimento pela própria Corte colombiana da doutrina da conexidade como critério de tutela desses direitos.

\section{A DOUTRINA DA CONEXIDADE COMO CRITÉRIO DE PROTEÇÃO DE DIREITOS SOCIAIS POR VIA DA AÇÃO DE TUTELA}

Conforme já apontado, o artigo 86 da Constituição colombiana assegura que, através da Ação de Tutela, toda pessoa possa, em procedimento preferente e sumário, reclamar perante os juízes, por si mesmo ou por alguém que atue em seu nome, a proteção imediata de direitos constitucionais fundamentais quando esses direitos sejam vulnerados ou ameaçados pela ação ou omissão de qualquer autoridade pública ${ }^{25}$.

A construção da doutrina da conexidade possibilitou a proteção dos direitos sociais pela Ação de Tutela diante do impasse no tratamento dos direitos sociais como direitos fundamentais de aplicação imediata. Nessa construção, a possibilidade da proteção, via Ação de Tutela de direitos sociais, demandaria que esses direitos estivessem ligados a direitos fundamentais de aplicação imediata, isto é, através da figura da conexidade, a Corte passasse a reconhecer que a indivisibilidade e interdependência dos direitos são manifestas, de modo a impedir que a violação de um direito que não fosse considerado uma liberdade clássica levasse à violação de um direito de liberdade propriamente dito. Isso significa dizer que a aceitação da tutela para os direitos econômicos, sociais e culturais somente caberia para os casos em que ocorresse a violação pela conexidade com um direito de liberdade, pois o direito

24 UPRIMNY, Rodrigo; GARCÍA VILLEGAS, Maurício. Tribunal constitucional e emancipação social na Colômbia. In: SANTOS, Boaventura de Sousa (org.). Democratizar a democracia: os caminhos da democracia participativa. Rio de Janeiro: Civilização Brasileira, 2002. p. 297-339.

25 BORDA, Luis Villar. Influencia de Kelsen en el actual sistema colombiano de control jurisdiccional de la Constitución. Revista Derecho del Estado, n. 9, p. 17-29, dez. 2000. Disponível em: http://revistas.uexternado.edu.co/index.php/derest/article/view/877/832. Acesso em: 9 maio 2018. 
fundamental, segundo a Corte colombiana, somente se caracterizaria pela sua conexão direta com os princípios constitucionais, pela sua eficácia direta e pelo seu conteúdo essencial. Nessa situação, o juiz poderia, na ausência do pronunciamento do legislador e, com o fim de adequar uma proteção imediata do direito, pronunciar-se sobre o alcance da norma no caso concreto e, se necessário, convocar a intervenção das autoridades competentes para uma prestação pelo Estado que colocasse fim à violação, considerada, ainda, a escassez de recursos e os propósitos de igualdade e justiça social, o que expressaria o enfrentamento pelo juiz de um problema de justiça distributiva ${ }^{26}$.

Catarina Santos Botelho esclarece que “[...] o Tribunal Constitucional colombiano já conferiu aplicação imediata a direitos prestacionais em conexão com direitos individuais, mediante uma adequada ponderação das circunstâncias específicas do caso concreto"27. E, nesse sentido, a doutrina da conexidade “[...] permite amparar direitos não tuteláveis judicialmente, em princípio, sempre e quando a sua proteção se requeria para reivindicação de um direito de caráter indiscutivelmente fundamental”28.

Assim, a partir da teoria da conexidade foi possível conferir proteção através de Ação de Tutela a direitos sociais, desde que a circunstância fática demonstre a conexão entre o direito social pleiteado e uma liberdade clássica, considerado, assim, o direito fundamental dentro dos parâmetros de conexão direta com os princípios constitucionais, pela sua eficácia direta e pelo seu conteúdo essencial.

Posteriormente, houve uma evolução no pensamento da Corte Constitucional, que, então, passou a admitir, como no caso da saúde, que a sua proteção pudesse se dar de forma autônoma através da Ação de Tutela, desde que o não reconhecimento do direito à saúde significasse lesão séria e direta à dignidade humana. Com isso, a Corte estendeu a proteção ao direito à saúde, pois a sua tutela não se daria mais apenas em conexidade com o direito à vida e à integridade pessoal, mas sim como direito fundamental autônomo, como se verifica na Sentença T-845, de 2006, ainda que nas situações explicitadas pela Corte ${ }^{29}$.

26 Nesse sentido, a sentença ${ }^{\circ}$ T-406/92. COLÔMBIA. Corte Constitucional. T-406/92. Primeira Sala de Revisão. Autor: José Manuel Rodríguez Rangel. Réu: Enrique Chartuny González, gerente da Empresas Públicas de Cartagena. Relator: Ciro Angarita Baron. Bogotá, 17 jun. 1992. Disponível em: http://www.corteconstitucional.gov.co/relatoria/1992/t-406-92.htm. Acesso em: 3 mar. 2018.

27 BOTELHO, Catarina Santos. Os direitos sociais em tempos de crise: ou revisitar as normas programáticas. Coimbra: Almedina, 2015.

28 Ibid. Com a ressalva de que: “A principal objeção a esta possibilidade prende-se, porém, com o fato de no domínio dos direitos civis e políticos, não se vislumbrar com clareza a extensão da sua vertente social, nem se poderem deduzir pontos de referência para ponderar prioridades na atribuição e ponderação do orçamento estatal".

29 COLÔMBIA. Corte Constitucional. T-845/06. Quarta Sala de Revisão. Autor: Elena Vargas Bedoya, em nome de Maria Romelia Bedoya Tamayo. Ré: Direção Territorial de Saúde de Caldas. Relator: Jaime Córdoba Triviño. 
Mais adiante, a Corte firmou o entendimento, consoante se verifica da Sentença T760, de 2008, de que os direitos fundamentais deveriam ser identificados através de critérios materiais e não textuais, e que a Corte deveria garantir a aplicação progressiva dos direitos sociais. Ficou assentado nesse precedente que o direito à saúde tem um caráter fundamental e de aplicação imediata, sem que se deva provar sua conexidade com outros direitos fundamentais ${ }^{30}$.

Rodrigo Uprimny e García Villegas ${ }^{31}$ afirmam que a evolução da interpretação dada pela Corte colombiana à efetividade dos direitos sociais explicita o ativismo judicial da Corte, ao considerarem a proteção de direitos sociais através da Ação de Tutela como uma amostra importante desse ativismo judicial, no sentido de que a proteção dos direitos sociais de forma sistemática passou a substituir a proteção que era procedida somente de maneira excepcional, isto é, quando a violação do direito social colocava em perigo outro direito de caráter fundamental, diante da teoria da conexidade.

A doutrina da conexidade possibilitou, assim, a inicial proteção dos direitos sociais através da Ação de Tutela, quando não se admitia possível que sua proteção ocorresse diretamente a partir do texto constitucional, o que propiciou a evolução do entendimento da Corte colombiana, que passou a admitir na tutela de direitos sociais, como no caso da saúde, o seu caráter de direito de fundamental autônomo e de aplicação imediata, sem que se necessite mais provar sua conexidade com outros direitos fundamentais.

\section{AS TIPOLOGIAS DE SENTENÇA SOBRE DIREITOS SOCIAIS DA CORTE COLOMBIANA}

A doutrina constitucional colombiana estuda e classifica as decisões da Corte Constitucional de diversas maneiras, de forma a sistematizar e compreender seus efeitos e modulações. Hernán García ${ }^{32}$, por exemplo, a partir dos critérios de interpretação que a Corte tem utilizado desde 1992 para suas decisões, classifica vinte e um tipos de sentenças,

Bogotá, 13 out. 2006. Disponível em: http://www.corteconstitucional.gov.co/relatoria/2006/t-845-06.htm. Acesso em: 10 maio 2018.

30 MELlO, Patrícia Perrone Campos; CHEVITARESE, Alessia Barroso Lima Brito Campos (coord. geral). Casoteca da América Latina. Revista Publicum, Rio de Janeiro, v. 3, n. 2, p. 286-338, 2017. Disponível em: http://www.e-publicacoes.uerj.br/index.php/publicum/article/view/31883. Acesso em: 7 abr. 2018.

31 UPRIMNY, Rodrigo; GARCÍA VILLEGAS, Maurício. Tribunal constitucional e emancipação social na Colômbia. In: SANTOS, Boaventura de Sousa (org.). Democratizar a democracia: os caminhos da democracia participativa. Rio de Janeiro: Civilização Brasileira, 2002. p. 297-339.

32 GARCÍA, Hernán Alejandro Olano. Tipología de nuestras sentencias constitucionales. Vniversitas, n. 108, p. 571-602, dez. 2004. Disponível em: http://www.redalyc.org/articulo.oa?id=82510813. Acesso em: 10 maio 2018. 
organizadas em seis classes de modulação, sendo essas: modulação tradicional, modulações que afetam o conteúdo (ou sentenças "manipulativas"), modulações relativas ao efeito temporal (ou prospectivas), modulações do Direito dos juízes, modelos específicos da Corte Constitucional colombiana, além de outros modelos sem modulação.

Dentre essas classes de modulação, Hernán García ${ }^{33}$ destaca, ainda, no caso das sentenças de modulação, uma subdivisão chamada Jurisprudência pop, em alusão a um tipo de música ligeira e popular, um estilo musical pop, derivado de estilos musicais negros e da música folclórica britânica.

Para além das classificações quanto à modulação das sentenças, a doutrina constitucional colombiana classifica ainda de outras formas as decisões da Corte

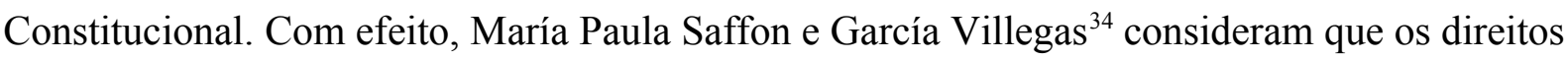
sociais fornecem uma classificação das sentenças sobre direitos sociais prestacionais ou sentenças sobre direitos sociais em geral, pois variam quanto a seu objeto e seus efeitos de uma maneira muito relevante. As sentenças sobre direitos sociais prestacionais referem-se aos casos relacionados com um direito social, econômico ou cultural previsto pela Constituição de 1991, e que impliquem uma decisão econômica acerca de um serviço ou um subsídio que deva ser ou não concedido a um indivíduo ou a um grupo de pessoas, geralmente, como dever do Estado. A título exemplificativo lista-se o pagamento de uma aposentadoria, a construção de uma casa, a aprovação de um terreno para uma escola pública. As sentenças sobre direitos sociais em geral incluem casos que se ligam a um direito classificado como social, econômico ou cultural pela Carta, mas não implicam uma decisão essencialmente "econômica" 35 .

A análise de tais tipologias é importante para a compreensão das sentenças, considerados a quantidade e o volume de cada uma delas, como também o número de provimentos ou desprovimentos, de modo a se perscrutar a jurisdição constitucional como mecanismo de emancipação social, conforme apontam os estudos realizados por María Paula Saffon e García Villegas e sintetizados na tabela a seguir:

33 GARCÍA, Hernán Alejandro Olano. Tipología de nuestras sentencias constitucionales. Vniversitas, n. 108, p. 571-602, dez. 2004. Disponível em: http://www.redalyc.org/articulo.oa?id=82510813. Acesso em: 10 maio 2018. 34 SAFFON, María Paula; GARCÍA VILLEGAS, Mauricio. Derechos sociales y activismo judicial. La dimensión fáctica del activismo judicial en derechos sociales en Colombia. Revista Estudios Socio-Jurídicos, v. 13, n. 1, p. 75-107, jan./jun. 2011. Disponível em: http://www.redalyc.org/html/733/73318918004/. Acesso em: 05 dez. 2017.

35 Ibid. 
TABELA 1 - Distribuição das sentenças sobre direitos sociais no período de 1992 a 2006

\begin{tabular}{cccc}
\hline $\begin{array}{c}\text { Tipos de decisões sobre } \\
\text { direitos sociais }\end{array}$ & $\begin{array}{c}\text { \% do total de } \\
\text { decisões sobre } \\
\text { direitos sociais }\end{array}$ & $\begin{array}{c}\text { \% de decisões } \\
\text { concedidas }\end{array}$ & $\begin{array}{c}\text { \% de decisões } \\
\text { negadas }\end{array}$ \\
\hline Direitos sociais prestacionais & $76 \%$ & $71 \%$ & $28 \%$ \\
Direitos sociais em geral & $24 \%$ & $50 \%$ & $50 \%$ \\
Total & $\begin{array}{c}100 \%(55 \% \text { do total de } \\
\text { tutelas })\end{array}$ & Não aplicável & Não aplicável \\
\hline
\end{tabular}

Fonte: Tabela adaptada a partir da apresentada por Saffon e García Villegas (tradução nossa) ${ }^{36}$.

Verifica-se que, no período de 1992 a 2006, a quantidade de sentenças procedentes em matéria de proteção de direitos sociais prestacionais foi muito maior do que a relativa às sentenças que negaram a tutela, o que reflete um importante grau de ativismo judicial em direitos sociais. Diante desse cenário, a proteção judicial dos direitos sociais prestacionais implica a expedição de uma ordem, na maioria das vezes dirigida ao Estado, para que pague ou proveja um serviço ${ }^{37}$.

Portanto, a análise realizada, consideradas as tipologias de sentenças de tutela de direitos sociais pela Corte colombiana, assim como o índice de procedência de tutelas em direitos sociais, reflete a atuação da Corte e seu ativismo em matéria de direitos sociais, o que pode levar à conclusão acerca da jurisdição constitucional como instrumento de emancipação social, o que não se faz possível sem o exame também do teor das sentenças da Corte, ainda que se faça a partir de algumas de suas decisões paradigmáticas.

\section{DECISÕES PARADIGMÁTICAS DA CORTE COLOMBIANA NA PROTEÇÃO DE DIREITOS SOCIAIS}

O ativismo da Corte colombiana é mais bem compreendido pelo teor de suas sentenças, especialmente diante daquelas consideradas paradigmáticas.

Destacam-se algumas decisões que expressam claramente a missão constitucional assumida pela Corte colombiana em proteção dos direitos sociais, sobretudo diante de determinados grupos étnicos, minorias e setores em situação de fragilidade social e

36 SAFFON, María Paula; GARCÍA VILlEGAS, Mauricio. Derechos sociales y activismo judicial. La dimensión fáctica del activismo judicial en derechos sociales en Colombia. Revista Estudios Socio-Jurídicos, v. 13, n. 1, p. 75-107, jan./jun. 2011. Disponível em: http://www.redalyc.org/html/733/73318918004/. Acesso em: 05 dez. 2017.

37 Ibid. 
econômica. Referidas decisões denotam o comportamento progressista da Corte, especificamente em matéria de direitos sociais ${ }^{38}$.

Com efeito, ressaltam-se as decisões sobre a proteção de minorias étnicas, culturais e autonomia individual, como no caso da descriminalização do uso das drogas, na sentença C221/94; sobre eutanásia, na sentença C-239/97; ou contra a discriminação contra os homossexuais, como na sentença T-097/94; de proteção da intimidade dos homossexuais na Força Pública, na sentença C-507/99; de proibição da penalização de militar por ser homossexual, na sentença T-100/98; e da vedação da expulsão de aluno por comportamentos homossexuais ou de penalização de docente por esse motivo, na sentença C-481/98 ${ }^{39}$.

Rodrigo Uprimny ${ }^{40}$ observa, contudo, que a Corte colombiana nem sempre é progressista, mas que conseguiu, em grande medida, o alcance do pluralismo e favoreceu não somente a igualdade entre as religiões, mediante a anulação da concordata e dos privilégios da religião católica, mas também reconheceu esferas muito amplas para o exercício da administração da justiça por autoridades indígenas.

No âmbito da proteção de direitos sociais, destaca Rodrigo Uprimny ${ }^{41}$ dois tipos de intervenções: i) o controle abstrato ou geral de constitucionalidade, referindo-se especificamente a leis de conteúdo econômico; e ii) a proteção individual ou de grupos, por meio da Ação de Tutela.

No primeiro grupo, o do controle abstrato de constitucionalidade, destacam-se as decisões de interferência na política econômica em favor dos direitos sociais. Rodrigo Uprimny ${ }^{42}$ observa que a Corte colombiana condicionou fortemente a política econômica, ao declarar inconstitucionais, total ou parcialmente, determinadas leis com repercussões em custos econômicos e orçamentários muito importantes, como as que estendiam o imposto sobre valor agregado a produtos de primeira necessidade, na sentença C-776/03; a de indexação parcial dos salários dos servidores públicos, nas sentenças C-1433/00, C-1064/01 e

38 Para uma análise mais completa e elucidativa de decisões paradigmáticas da Corte colombiana na proteção de direito sociais, ver Casoteca da América Latina. MELLO, Patrícia Perrone Campos; CHEVITARESE, Alessia Barroso Lima Brito Campos (coord. geral). Casoteca da América Latina. Revista Publicum, Rio de Janeiro, v. 3, n. 2, p. 286-338, 2017. Disponível em: http://www.e-publicacoes.uerj.br/index.php/publicum/article/view/31883. Acesso em: 7 abr. 2018.

39 UPRIMNY YEPES, Rodrigo. A judicialização da política na Colômbia: casos, potencialidades e riscos. Sur, Rev. int. direitos human., São Paulo, v. 4, n. 6, p. 52-69, 2007. Disponível em: http://www.scielo.br/scielo.php? script=sci_arttext\&pid=S1806-64452007000100004\&lng=en\&nrm=iso. Acesso em: 3 maio 2018.

40 UPRIMNY, Rodrigo; GARCÍA VILLEGAS, Maurício. Tribunal constitucional e emancipação social na Colômbia. In: SANTOS, Boaventura de Sousa (org.). Democratizar a democracia: os caminhos da democracia participativa. Rio de Janeiro: Civilização Brasileira, 2002. p. 297-339.

41 Ibid.

42 UPRIMNY YEPES, op. cit. 
C-1017/03; a de extensão de alguns benefícios de pensão a certos grupos populacionais, ao considerar, na sentença C-409/94, que a restrição desconhecia o princípio de igualdade; ou de proibição, na sentença C-754/04, da modificação de certos regulamentos de pensão, por considerar que afetavam direitos adquiridos dos trabalhadores.

Essa interferência da Corte colombiana na política econômica em favor dos direitos sociais é muito clara no caso da intervenção na crise dos devedores hipotecários em 1998 e 1999, consoante a emblemática sentença C-700/99 ${ }^{43}$. Em 1997 a Colômbia entrou em grave recessão econômica que, combinada com certas decisões de política econômica, ocasionou uma situação muito difícil para milhares de pessoas de classe média, que assumiram hipotecas para adquirir casa própria e que, em poucos meses, poderiam perder suas moradias, cerca de noventa mil pessoas, cifra essa que se elevou, dois anos mais tarde, para duzentas mil famílias. Isso levou à atípica reunião em associações e marchas pacíficas visando a que o governo e o Congresso modificassem o sistema de financiamento, chamado UPAC, e dessem alívio aos devedores, o que não acatado acabou por levar às demandas perante a Corte Constitucional $^{44}$.

No que se refere à proteção individual ou de grupos, por meio da Ação de Tutela, destacam-se decisões em favor de populações estigmatizadas, como os encarcerados e os deslocados internos.

Nesse ponto, é de se atentar para as numerosas Ações de Tutela envolvendo as precárias condições do sistema carcerário, o que levou, na sentença T-762/15, à declaração, já pela terceira vez, do Estado de Coisas Inconstitucional do sistema penitenciário por violação estrutural de direitos fundamentais e de diversos direitos sociais. Antes a Corte já havia declarado o Estado de Coisas Inconstitucional no sistema penitenciário nas sentenças T$153 / 98$ e $\mathrm{T}-388 / 13^{45}$.

Já o caso paradigmático do deslocamento forçado foi apreciado na sentença T-025/04. In casu, a declaração de Estado de Coisas Inconstitucional pela Corte colombiana ${ }^{46}$ enfrentou

43 Mais detalhes sobre a sentença C-700/99 são encontrados na Casoteca da América Latina, Caso 7 Colômbia. MELlO, Patrícia Perrone Campos; CHEVITARESE, Alessia Barroso Lima Brito Campos. Casoteca da América Latina. Revista Publicum, v. 2, n. 5, p. 304-306, 2017. Disponível em: http://www.e-publicacoes.uerj.br/index.php/publicum/article/viewFile/31883/22573. Acesso em: 02 mar. 2018.

44 UPRIMNY, Rodrigo; GARCÍA VILLEGAS, Maurício. Tribunal constitucional e emancipação social na Colômbia. In: SANTOS, Boaventura de Sousa (org.). Democratizar a democracia: os caminhos da democracia participativa. Rio de Janeiro: Civilização Brasileira, 2002. p. 297-339.

45 Mais detalhes desse caso de violação estrutural de direitos fundamentais no sistema penitenciário colombiano, apreciado na sentença T-762/15, podem ser encontrados na Casoteca da América Latina, Caso 2 Colômbia. MELLO; CHEVITARESE, op. cit.

46 Sobre o tema, vale consultar: SANTOS, Ana Borges Coêlho. Direitos sociais pelo Poder Judiciário e seus reflexos em políticas públicas: uma perspectiva através das lides estruturais. 1. ed. Brasília: Del Rey, 2019; 
a violação massiva de direitos fundamentais, em termos de efetividade de direitos sociais, ordenou a adoção de "remédios estruturais" e, ainda, determinou a criação de um complexo sistema de monitoramento das ordens da Corte, de modo a garantir a eficácia da decisão ${ }^{47}$.

Dentre os direitos sociais abraçados pela Corte estão também os direitos trabalhistas. Antes de 1991, a estratégia legal dos sindicatos ficava reduzida à defesa de seus direitos através da negociação de acordos coletivos de trabalho, mas as decisões da Corte Constitucional nas Ações de Tutela acabaram por difundir uma nova cultura de negociação entre os sindicatos. Trata-se de uma cultura mais pragmática e menos centrada em princípios ideológicos imutáveis, o que foi facilitado pela proteção dos direitos dos trabalhadores, a partir dos próprios princípios constitucionais, e não da lei laboral, tendo sido desaprovadas certas práticas discriminatórias contra os trabalhadores sindicalizados, práticas que não violavam qualquer norma do código laboral, como, por exemplo, no caso da reintegração de trabalhadores sindicalizados que tinham sido despedidos, cumprindo-se todos os requisitos legais, mas com violação ao princípio de igualdade pelo fato de terem sido despedidos apenas trabalhadores sindicalizados; ou, ainda, no caso da Sentença T-568, de 1999, que determinou a readmissão de 209 trabalhadores sindicalizados, com fundamento em conceito da Organização Internacional do Trabalho ${ }^{48}$.

Ainda no âmbito dos direitos trabalhistas, o Tribunal proferiu, em 2010, a paradigmática Sentença T-629, sobre o direito ao trabalho dos profissionais do sexo ${ }^{49}$. Nesse caso, uma profissional do sexo que trabalhava em um bar teve seu direito ao trabalho reconhecido após engravidar. Foram, ainda, reconhecidos e reafirmados nessa decisão o direito à igualdade de tratamento, o direito à não discriminação no trabalho, seguridade social, dignidade, proteção da mulher gestante, licença maternidade e mínimo vital.

QUINAIA, Cristiano Aparecido; NUNES JÚNIOR, Vidal Serrano. Estado de coisas inconstitucional: do precedente colombiano ao leading case brasileiro. Revista Direitos Humanos e Democracia, v. 6, n. 12, p. 57-66, 2018. Disponível em: https://www.revistas.unijui.edu.br/index.php/direitoshumanosedemocracia/article/view/ 6852. Acesso em: 15 set. 2019; MEZA, Diego Armando Yáñez. El desplazamiento forzado en la jurisprudencia de la Corte Constitucional colombiana (1991-2003): momento previo a la declaratoria formal del Estado de Cosas Inconstitucional. Justicia, v. 18, n. 23, p. 191-218, 2013. Disponível em: http://revistas.unisimon.edu.co/index.php/justicia/article/view/1023. Acesso em: 15 set. 2019.

47 Detalhes sobre esse caso de violação estrutural de direitos fundamentais no deslocamento forçado que levou ao reconhecimento do Estado de Coisas Inconstitucional, apreciado na sentença T-025/04, podem ser encontrados na Casoteca da América Latina, Caso 1 Colômbia. MELLO, Patrícia Perrone Campos; CHEVITARESE, Alessia Barroso Lima Brito Campos. Casoteca da América Latina. Revista Publicum, v. 2, n. 5 , p. 304-306, 2017. Disponível em: http://www.e-publicacoes.uerj.br/index.php/publicum/article/viewFile/ 31883/22573. Acesso em: 02 mar. 2018.

48 UPRIMNY, Rodrigo; GARCÍA VILLEGAS, Maurício. Tribunal constitucional e emancipação social na Colômbia. In: SANTOS, Boaventura de Sousa (org.). Democratizar a democracia: os caminhos da democracia participativa. Rio de Janeiro: Civilização Brasileira, 2002. p. 297-339.

49 Esse caso, da sentença T-629, pode ser visto com mais detalhes na Casoteca da América Latina, Caso 9 Colômbia. MELLO; CHEVITARESE, op. cit. 
Além dos citados direitos sociais assegurados pela Corte, há outros de relevância protegidos por Sentenças em Ações de Tutela, como a sentença T-616/10 ${ }^{50}$, sobre o direito à água e ao saneamento básico de populações deslocadas; a sentença T-523/16 ${ }^{51}$, sobre o direito à educação de crianças com necessidades especiais; e a Sentença C-330/13 ${ }^{52}$, sobre a regulamentação especial e integral de Processo Penal envolvendo pessoas incapazes. Saffon e García Villegas demonstram o percentual das sentenças da Corte Constitucional sobre direitos sociais prestacionais entre 1992 e 2006, conforme tabela abaixo:

\section{TABELA 2 - Distribuição ponderada de sentenças da Corte Constitucional sobre direitos sociais prestacionais}

TIPO DE DIREITO SOCIAL AMPARADO

\begin{tabular}{cc}
\hline & Saúde (32\%) \\
Direitos sociais prestacionais em sentido estrito & Seguridade social (pensões) (14\%) \\
$(51 \%)$ & Saúde das crianças (3\%) \\
Educação das crianças (1\%) \\
Outros (1\%)
\end{tabular}

Fonte: Tabela adaptada a partir da tabela apresentada por Saffon e García Villegas (tradução nossa) ${ }^{53}$.

Observa-se nesse estudo apresentado por Saffon e García Villegas que a maior parte dos direitos sociais amparados pela Corte são referentes ao direito à saúde, com destaque para a sentença T-760/08, que reestruturou o Sistema de Saúde da Colômbia ${ }^{54}$.

A partir da análise desses casos é possível verificar que o ativismo da Corte Constitucional colombiana se espraiou pelo campo dos direitos sociais de forma acentuada e progressista, modificando o tratamento dado a esses direitos no ordenamento colombiano,

50 Mais detalhes desse caso, da sentença T-616/10, podem ser vistos na Casoteca da América Latina, Caso 6 Colômbia. MELLO, Patrícia Perrone Campos; CHEVITARESE, Alessia Barroso Lima Brito Campos. Casoteca da América Latina. Revista Publicum, v. 2, n. 5, p. 304-306, 2017. Disponível em: http://www.epublicacoes.uerj.br/index.php/publicum/article/viewFile/31883/22573. Acesso em: 02 mar. 2018.

$51 \mathrm{O}$ caso da sentença T-523/16 pode ser visto em mais detalhes na Casoteca da América Latina, Caso 8 Colômbia. Ibid.

52 COLÔMBIA. Corte Constitucional da Colômbia. Sentença n. C-330/13. Sala Plena. Autor: Enoc Rodríguez Gómez. Relator: Luis Ernesto Vargas Silva. Bogotá, 5 jun. 2013. Disponível em: http://www.corteconstitucional.gov.co/relatoria/2013/C-330-13.htm. Acesso em: 10 maio 2018.

53 SAFFON, María Paula; GARCÍA VILLEGAS, Mauricio. Derechos sociales y activismo judicial. La dimensión fáctica del activismo judicial en derechos sociales en Colombia. Revista Estudios Socio-Jurídicos, v. 13, n. 1, p. 75-107, jan./jun. 2011. Disponível em: http://www.redalyc.org/html/733/73318918004/. Acesso em: 05 dez. 2017.

54 Quanto a essa decisão, é de se observar o relatado no Caso 3 Colômbia da Casoteca da América Latina. MELLO; CHEVITARESE, op. cit. 
cujo conteúdo tem evidente potencial de impactar a sociedade, embora ainda seja necessário aferir se efetivamente a jurisdição constitucional se apresenta como mecanismo de emancipação social.

\section{A EFETIVIDADE DAS DECISÕES DA CORTE COLOMBIANA COMO MECANISMO DE EMANCIPAÇÃO SOCIAL}

O direito pode ser utilizado para reavivar a esperança coletiva. A esperança em uma sociedade melhor tem, como a maioria dos valores coletivos fundamentais, vertentes. Uma está relacionada com a aceitação e confiança no presente e a outra se refere à possibilidade de obtenção de uma mudança futura, a partir da ação no presente ${ }^{55}$. É nesse sentido que se procura saber, através das decisões da Corte colombiana na proteção dos direitos sociais, se acabam se perfazendo apenas em formalidade ou de repercussão pontual, ou se têm valor impactante na realidade social, a ponto de possibilitar à jurisdição constitucional tornar-se um mecanismo de emancipação social.

Assim, é preciso reconhecer, como alertam Rodrigo Uprimny e García Villegas ${ }^{56}$, que a incidência social das decisões judiciais pode não ser suficiente por si mesma para produzir mudanças sociais diretas e efetivas, nem ser considerada irrelevante, sob a perspectiva de avaliação de certas mudanças sociais. Essa reflexão incide na análise do complexo fenômeno sobre qual tipo de relação ou de encadeamento existe entre direito progressista e emancipação social. Isso porque, não sendo uma relação de simples causalidade, impõe-se o estudo das condições ou dos fatores que permitem que a decisão judicial tenha incidência sobre a emancipação social, dos quais se destacam: 1) o tipo de decisão judicial; 2) o tipo de contexto social em que a decisão é tomada; 3) o tipo de ator social que recebe a decisão; 4) o tipo de estratégia predominante na luta política do ator social; e 5) o tipo de meio internacional em que se desenvolvem as práticas emancipatórias.

Rodrigo Uprimny e García Villegas ${ }^{57}$ observam que nem toda decisão progressista produz emancipação social, e que nem sempre seus objetivos se cumprem ou, caso sejam

\footnotetext{
55 SAFFON, María Paula; GARCÍA VILLEGAS, Mauricio. Derechos sociales y activismo judicial. La dimensión fáctica del activismo judicial en derechos sociales en Colombia. Revista Estudios Socio-Jurídicos, v. 13, n. 1, p. 75-107, jan./jun. 2011. Disponível em: http://www.redalyc.org/html/733/73318918004/. Acesso em: 05 dez. 2017.

56 UPRIMNY, Rodrigo; GARCÍA VILLEGAS, Maurício. Tribunal constitucional e emancipação social na Colômbia. In: SANTOS, Boaventura de Sousa (org.). Democratizar a democracia: os caminhos da democracia participativa. Rio de Janeiro: Civilização Brasileira, 2002. p. 297-339.

57 Ibid.
} 
cumpridos, isso pode ocorrer em níveis diversos. Assim, uma maior efetividade emancipatória das decisões progressistas do Tribunal ocorre quando se combinam os seguintes fatores: decisões judiciais (remediais), preferentemente de não fazer (proibições), recebidas em contextos ou auditórios consensuais, apropriadas politicamente por movimentos quer dispersos quer comunitários, os quais adotam a estratégia jurídica como parte constitutiva da sua luta política e da sua identidade como movimento e contam com vínculos internacionais de apoio.

A análise caso a caso pode levar à conclusão acerca do resultado efetivo ou não em relação à emancipação social. Nesse sentido, merece análise o caso dos devedores hipotecários e sistema UPAC, consoante apreciado na sentença T-700/99 ${ }^{58}$.

A crise econômica pela qual passou a Colômbia, iniciada em 1997, criou uma difícil situação para milhares de pessoas de classe média, que assumiram hipotecas para adquirir casa própria e que corriam o risco de perderem suas casas. A gravidade da situação levou a se associarem para se defenderem contra as entidades financeiras. Quando a questão chegou à Corte colombiana, por meio de diversas Ações de Tutela, as decisões, em sua maioria, foram favoráveis aos devedores. O que se indaga é quais teriam sido as consequências práticas, se foram as decisões capazes de tornar efetivo o direito social à moradia e se promoveram emancipação social.

Entre os anos de 1998 e 1999, foram proferidas várias sentenças sobre o sistema UPAC que, em geral, tendiam a proteger os devedores hipotecários. A UPAC ficou vinculada à inflação, foi proibida a capitalização de juros e foi ordenada uma nova liquidação dos créditos hipotecários para aliviar, assim, a situação dos devedores. Além disso, o Tribunal ordenou que no prazo de sete meses fosse elaborada uma nova legislação que regulasse o financiamento para a compra de habitação própria. Porém, nesse contexto, a Assembleia Nacional discutiu e aprovou, no final de 1999, uma nova lei de financiamento de habitação, que incorporava, entre outras coisas, perdão aos devedores no valor de dois bilhões de pesos (em média, 1.200 milhões de dólares). Daí a conclusão de que as sentenças da Corte Constitucional levaram à modificação imediata do sistema UPAC, diante da crise social que estava a desencadear ${ }^{59}$.

58 O caso dos devedores hipotecários e sistema UPAC, da sentença T-700/99, está relatado na Casoteca da América Latina, Caso 7 Colômbia. MELLO, Patrícia Perrone Campos; CHEVITARESE, Alessia Barroso Lima Brito Campos. Casoteca da América Latina. Revista Publicum, v. 2, n. 5, p. 304-306, 2017. Disponível em: http://www.e-publicacoes.uerj.br/index.php/publicum/article/viewFile/31883/22573. Acesso em: 02 mar. 2018. 59 UPRIMNY, Rodrigo; GARCÍA VILLEGAS, Maurício. Tribunal constitucional e emancipação social na Colômbia. In: SANTOS, Boaventura de Sousa (org.). Democratizar a democracia: os caminhos da democracia participativa. Rio de Janeiro: Civilização Brasileira, 2002. p. 297-339. 
Contudo, afirmam Rodrigo Uprimny e García-Villegas não ser fácil a tarefa de avaliação do potencial emancipador do movimento dos devedores hipotecários e da jurisprudência do Tribunal, ainda que não haja qualquer dúvida de que foram as sentenças da Corte que permitiram um certo alívio financeiro a um importante número de devedores e que, talvez em consequência disso, não tenham perdido suas casas, além de os devedores verem aumentadas as possibilidades de se defenderem diante de eventuais ações de despejo. Consideram, ainda, que o litígio constitucional permitiu uma maior articulação entre os devedores e as suas associações, em uma espécie de movimento social contra o setor financeiro e a política estatal de habitação, tendo a justiça constitucional proporcionado o dinamismo do movimento quando conferiu visibilidade política aos devedores e às suas associações e quando modificou o sentido das suas intervenções, consideradas não queixas isoladas de devedores, mas sim de uma tomada de posição coletiva, com o aval da Corte, que pôs em questão a política estatal de habitação e o comportamento das entidades financeiras ${ }^{60}$.

Portanto, nesses casos específicos dos devedores hipotecários e sistema UPAC, a jurisdição constitucional da Corte se perfez em mecanismo de emancipação social, pois, além de ter aliviado financeiramente um relevante número de devedores que, talvez em consequência disso, não tenham perdido as suas casas e de ter aumentado as possibilidades de defesa em caso de ações de despejo, ocasionou uma maior articulação entre os devedores e as suas associações, impulsionando um movimento social contra o setor financeiro e a política estatal de habitação.

Reafirma-se, portanto, que a análise da repercussão das decisões da Corte Constitucional como mecanismo de emancipação social é complexa e precisa ser feita caso a caso, não podendo ser generalizada. Ademais, há riscos e limites que não podem ser desconsiderados, como alertam Rodrigo Uprimny García-Villegas ${ }^{61}$ quanto aos casos dos devedores hipotecários e sistema UPAC, pois desses casos não se pode inferir que venham a produzir um maior acesso futuro à habitação por parte dos setores pobres ou que a Corte não tenha protegido, com custos fiscais importantes, sobretudo devedores hipotecários da classe média ou, ainda, que a estratégia jurídica não tenha limitado também as potencialidades das

60 SAFFON, María Paula; GARCÍA VILLEGAS, Mauricio. Derechos sociales y activismo judicial. La dimensión fáctica del activismo judicial en derechos sociales en Colombia. Revista Estudios Socio-Jurídicos, v. 13, n. 1, p. 75-107, jan./jun. 2011. Disponível em: http://www.redalyc.org/html/733/73318918004/. Acesso em: 05 dez. 2017.

61 UPRIMNY, Rodrigo; GARCÍA VILLEGAS, Maurício. Tribunal constitucional e emancipação social na Colômbia. In: SANTOS, Boaventura de Sousa (org.). Democratizar a democracia: os caminhos da democracia participativa. Rio de Janeiro: Civilização Brasileira, 2002. p. 297-339. 
associações de devedores, ainda porque algumas teriam se convertido em simples centros de recepção de queixas específicas acerca das dificuldades de nova liquidação dos créditos.

Outros riscos e limites podem aparecer em cada situação fática e a jurisdição constitucional pode acabar ficando limitada, inclusive por temor ou pela própria ação do Congresso, razão pela qual a jurisdição constitucional deva ser apoiada por um constitucionalismo militante e que seja capaz de tornar realidade as promessas da Constituição ${ }^{62}$.

Mas é possível afirmar, na esteira de María Paula Saffon e García Villegas ${ }^{63}$, que o ativismo da Corte colombiana em direitos sociais não apenas cumpre a função de insistir na necessidade de aplicação direta dos direitos sociais e, em consequência, de uma mudança social, mas também cumpre uma função legitimadora a atenuar a tensão existente entre o discurso aspiracional da Constituição e uma realidade cheia de limitações e dificuldades institucionais que impedem a sua materialização, sem deixar de possibilitar a retórica da solidariedade para manter a esperança da cidadania e da mudança social, e sem que se fechem as portas para uma luta social e política mais ampla em face do conteúdo emancipatório dos direitos sociais.

Daí a advertência que produzem no sentido de que as constituições aspiracionais e as interpretações progressistas de seu conteúdo podem funcionar como uma estratégia contra a decepção e o desespero, mas também podem ser levadas a sério e serem utilizadas como uma ferramenta para produzir mudanças sociais, o que significa um otimismo moderado e constitutivo como uma forma de pensar seriamente a emancipação social ${ }^{64}$. E é nesse sentido que a jurisdição constitucional pode ser um mecanismo de emancipação social.

\section{CONCLUSÃO}

O presente trabalho empreendeu uma análise sobre a jurisdição constitucional como mecanismo de emancipação social, a partir do ativismo progressista da Corte Constitucional da Colômbia na realização dos direitos sociais. Ficou claro que essa análise demandou primeiramente a contextualização do ambiente histórico e institucional que levou à atual

62 SAFFON, María Paula; GARCÍA VILlEGAS, Mauricio. Derechos sociales y activismo judicial. La dimensión fáctica del activismo judicial en derechos sociales en Colombia. Revista Estudios Socio-Jurídicos, v. 13, n. 1, p. 75-107, jan./jun. 2011. Disponível em: http://www.redalyc.org/html/733/73318918004/. Acesso em: 05 dez. 2017.

63 Ibid.

64 Ibid. 
Constituição colombiana de 1991 e à Corte Constitucional que então se implantou. O primeiro desafio da Corte, na interação de um extenso catálogo de direitos inscritos no texto constitucional, foi assumir o papel protagonista em prol da implementação desses direitos. A partir daí, descortinaram-se seus obstáculos históricos, a omissão dos demais atores públicos e sociais na sua realização e o ativismo judicial, como caminho a materializar as aspirações da nova Constituição.

A Corte Constitucional colombiana, no processo de evolução dos direitos sociais, utilizou primeiramente a doutrina da conexidade, de modo a possibilitar que a Ação de Tutela pudesse ser empregada para a proteção dos direitos sociais, diante do impasse no tratamento dos direitos sociais como direitos fundamentais de aplicação imediata. Nessa construção, foi possível a proteção, via Ação de Tutela de direitos sociais, desde que a lesão a esses direitos causasse a violação de um direito de liberdade.

Posteriormente, passou a admitir a proteção de direito social, sem a necessidade da comprovação da conexidade, como direito fundamental autônomo, mas desde que cumpridos alguns requisitos, como no caso do direito à saúde, em que se deveria demonstrar que o não reconhecimento do direito à saúde significaria lesão séria e direta à dignidade humana e que se tratava de uma pessoa em situação de proteção constitucional especial ou implicasse deixar a pessoa em uma condição de vulnerabilidade por falta de condição econômica.

Em momento seguinte, a Corte passou a entender que os direitos fundamentais deveriam ser identificados através de critérios materiais e não textuais e, assim, que deveria garantir a aplicação progressiva dos direitos sociais, quando, então, assentou o entendimento de que o direito à saúde tem um caráter fundamental e de aplicação imediata, sem que se deva provar sua conexidade com outros direitos fundamentais.

Essa postura da Corte colombiana espelha um ativismo progressista que se manifesta além dos direitos sociais, como se pôde verificar através da análise das tipologias das sentenças proferidas pela Corte, o que também levou à observação de que os direitos sociais podem ser divididos, nessa tipologia de sentenças, em direitos sociais prestacionais e não prestacionais, especialmente diante da sua repercussão na esfera dos órgãos públicos que terão que assumir o encargo da satisfação das prestações, o que possibilitou, ainda, observar o ativismo da Corte através da quantidade de sentenças de procedência e de improcedência, para se aferir se os pleitos em matéria de direitos sociais são acolhidos ou não e em que proporção. 
Verifica-se que o ativismo progressista da Corte colombiana é melhor compreendido, sobretudo, a partir do exame do conteúdo de suas decisões, o que se fez através de decisões paradigmáticas da Corte na proteção de direitos sociais, com o intento final de aferir a efetividade das decisões e a jurisdição constitucional como mecanismo de emancipação social. Com efeito, a partir do caso específico dos devedores hipotecários e sistema UPAC, foi possível concluir que a jurisdição constitucional da Corte Constitucional colombiana é um importante mecanismo de emancipação social, embora apresente riscos, inclusive o de inibição da cidadania mais diretamente ativa.

Por fim, denota-se que o ativismo progressista da Corte colombiana promove a realização do conteúdo emancipatório dos direitos sociais, o que possibilita a intervenção da jurisdição constitucional na tensão que se forma entre o discurso aspiracional da Constituição colombiana e uma realidade de muitas dificuldades, inclusive institucionais, sem que se deixe de atentar para o necessário cuidado de que, ao contribuir com a mudança social, não sufoque os movimentos sociais, e sirva sim de mais um instrumento da cidadania na construção de uma sociedade melhor.

\section{REFERÊNCIAS}

BORDA, Luis Villar. Influencia de Kelsen en el actual sistema colombiano de control jurisdiccional de la Constitución. Revista Derecho del Estado, n. 9, p. 17-29, dez. 2000. Disponível em: http://revistas.uexternado.edu.co/index.php/derest/article/view/877/832. Acesso em: 9 maio 2018.

BOTELHO, Catarina Santos. Os direitos sociais em tempos de crise: ou revisitar as normas programáticas. Coimbra: Almedina, 2015.

BRINKS, Daniel M.; BLASS, Abby. The DNA of constitutional justice in Latin America: politics, governance and judicial design. New York, NY: Cambridge University Press, 2018.

COLÔMBIA. Constitución Politica de Colombia, de 6 de julho de 1991. Disponível em: http://www.corteconstitucional.gov.co/inicio/Constitucion\%20politica\%20de \%20Colombia.pdf. Acesso em: 3 maio 2018.

COLÔMBIA. Corte Constitucional. Sentença n. C-330/13. Sala Plena. Autor: Enoc Rodríguez Gómez. Relator: Luis Ernesto Vargas Silva. Bogotá, 5 jun. 2013. Disponível em: http://www.corteconstitucional.gov.co/relatoria/2013/C-330-13.htm . Acesso em: 10 maio 2018.

COLÔMBIA. Corte Constitucional. Sentença $n^{\circ}$ T-427/92. Segunda Sala de Revisão. Autor: Luis Hernando Suarez Pineda. Relator: Eduardo Cifuentes Muñoz. Bogotá, 24 jun. 1992. 
Disponível em: http://www.corteconstitucional.gov.co/relatoria/1992/t-427-92.htm. Acesso em: 2 mar. 2018.

COLÔMBIA. Corte Constitucional. T-406/92. Primeira Sala de Revisão. Autor: José Manuel Rodríguez Rangel. Réu: Enrique Chartuny González, gerente da Empresas Públicas de Cartagena. Relator: Ciro Angarita Baron. Bogotá, 17 jun. 1992. Disponível em:

http://www.corteconstitucional.gov.co/relatoria/1992/t-406-92.htm. Acesso em: 3 mar. 2018.

COLÔMBIA. Corte Constitucional. T-845/06. Quarta Sala de Revisão. Autor: Elena Vargas Bedoya, em nome de Maria Romelia Bedoya Tamayo. Ré: Direção Territorial de Saúde de Caldas. Relator: Jaime Córdoba Triviño. Bogotá, 13 out. 2006. Disponível em: http://www.corteconstitucional.gov.co/relatoria/2006/t-845-06.htm. Acesso em: 10 maio 2018.

FAO Colombia. Programa de resiliência (2017-2020). Disponível em: http://www.fao.org/3/a-i7584s.pdf. Acesso em: 8 maio 2018.

GARCÍA VILLEGAS, Mauricio. Constitucionalismo aspiracional. Araucaria. Revista Iberoamericana de Filosofia, Política y Humanidades, v. 15, n. 29, 2013. Disponível em: http://www.redalyc.org/html/282/28225781004/. Acesso em: 28 maio 2017.

GARCÍA VILLEGAS, Mauricio. Constitucionalismo aspiracional: derecho, democracia y cambio social en América Latina. Análisis Político, v. 25, n. 75, p. 89-110, maio 2012. Disponível em: https://revistas.unal.edu.co/index.php/anpol/article/view/43508/44797. Acesso em: 15 abr. 2018.

GARCÍA, Hernán Alejandro Olano. Tipología de nuestras sentencias constitucionales. Vniversitas, n. 108, p. 571-602, dez. 2004. Disponível em: http://www.redalyc.org/articulo.oa?id=82510813. Acesso em: 10 maio 2018.

LANDAU, David. Judicial role and the limits of constitutional convergence in Latin America". In: DIXON, Rosalind; GINSBURY, Tom (ed.). Comparative Constitutional Law in Latin America, 2017. Disponível em: https://ssrn.com/abstract=2907075. Acesso em: 9 abr. 2018.

MELlO, Patrícia Perrone Campos; CHEVITARESE, Alessia Barroso Lima Brito Campos (coord. geral). Casoteca da América Latina. Revista Publicum, Rio de Janeiro, v. 3, n. 2, p. 286-338, 2017. Disponível em:

http://www.e-publicacoes.uerj.br/index.php/publicum/article/view/31883. Acesso em: 7 abr. 2018.

MELLO, Patrícia Perrone Campos; CHEVITARESE, Alessia Barroso Lima Brito Campos. Casoteca da América Latina. Revista Publicum, v. 2, n. 5, p. 304-306, 2017. Disponível em: http://www.e-publicacoes.uerj.br/index.php/publicum/article/viewFile/31883/22573. Acesso em: 02 mar. 2018.

MEZA, Diego Armando Yáñez. El desplazamiento forzado en la jurisprudencia de la Corte Constitucional colombiana (1991-2003): momento previo a la declaratoria formal del Estado 
de Cosas Inconstitucional. Justicia, v. 18, n. 23, p. 191-218, 2013. Disponível em: http://revistas.unisimon.edu.co/index.php/justicia/article/view/1023. Acesso em: 15 set. 2019.

MOLINA, Jorge Enrique León. Constitucionalismo aspiracional y paz: entre la democracia y la opinión. Soft Power, v. 3, n. 1, p. 209-218, 2017.

NEIRA, Enrique. Un caso intrincado de violencia: Colombia. Nueva Sociedad, n. 105, p. 141152, jan./fev. 1990. Disponível em: http://nuso.org/media/articles/downloads/1840_1.pdf. Acesso em: 9 maio 2018.

QUINAIA, Cristiano Aparecido; NUNES JÚNIOR, Vidal Serrano. Estado de coisas inconstitucional: do precedente colombiano ao leading case brasileiro. Revista Direitos Humanos e Democracia, v. 6, n. 12, p. 57-66, 2018. Disponível em: https://www.revistas.unijui.edu.br/index.php/direitoshumanosedemocracia/article/view/6852. Acesso em: 15 set. 2019.

REVENGA-SÁNCHEZ, Miguel; GIRÓN-REGUERA, Emilia. La Corte Constitucional colombiana ante las medidas de seguridad y defensa nacional del gobierno de Uribe". Estudios Socio-Jurídicos, v. 6, n. 1, p. 29-57, jan./jun. 2004. Disponível em: https://revistas.urosario.edu.co/index.php/sociojuridicos/article/view/274/223. Acesso em: 1 maio 2018.

SAFFON, María Paula; GARCÍA VILLEGAS, Mauricio. Derechos sociales y activismo judicial. La dimensión fáctica del activismo judicial en derechos sociales en Colombia. Revista Estudios Socio-Jurídicos, v. 13, n. 1, p. 75-107, jan./jun. 2011. Disponível em: http:// www.redalyc.org/html/733/73318918004/. Acesso em: 05 dez. 2017.

SANTOS, Ana Borges Coêlho. Direitos sociais pelo Poder Judiciário e seus reflexos em políticas públicas: uma perspectiva através das lides estruturais. 1. ed. Brasília: Del Rey, 2019.

TORRES, Escobar Sebastián; VARGAS, Luis Mario Hernández; FRANCO, Christhian Miguel Salcedo. El juez constitucional como garante de los derechos sociales en Colombia: una mirada crítica al activismo judicial de la Corte Constitucional colombiana. Univ. Estud. Bogotá, n. 10, p. 125-155, jan./dez. 2013. Disponível em:

http://cienciasjuridicas.javeriana.edu.co/documents/3722972/4350738/7+el+juez+constitucion al+125-156.pdf/6f7d3646-64d7-4f90-bab0-7a370cd777be. Acesso em: 13 dez. 2017.

UPRIMNY YEPES, Rodrigo. A judicialização da política na Colômbia: casos, potencialidades e riscos. Sur, Rev. int. direitos human., São Paulo, v. 4, n. 6, p. 52-69, 2007. Disponível em: http://www.scielo.br/scielo.php?script=sci_arttext\&pid=S180664452007000100004\&lng=en\&nrm=iso. Acesso em: 3 maio 2018.

UPRIMNY, Rodrigo; GARCÍA VILLEGAS, Maurício. Tribunal constitucional e emancipação social na Colômbia. In: SANTOS, Boaventura de Sousa. Democratizar a democracia: os caminhos da democracia participativa. Rio de Janeiro: Civilização Brasileira, 2002. p. 297-339. 
UPRIMNY, Rodrigo; GARCÍA VILLEGAS, Maurício. Tribunal constitucional e emancipação social na Colômbia. In: SANTOS, Boaventura de Sousa (org.). Democratizar a democracia: os caminhos da democracia participativa. Rio de Janeiro: Civilização Brasileira, 2002. p. 297-339.

\section{DADOS DA PUBLICAÇÃO}

Categoria: artigo submetido ao double-blind review.

Recebido em: 05/07/2018.

Aceito em: 03/10/2019. 
